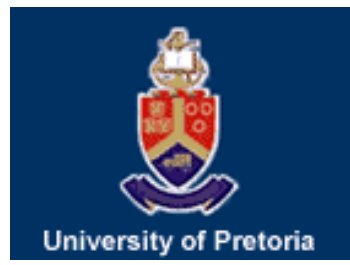

University of Pretoria

Department of Economics Working Paper Series

Comparing South African Inflation Volatility across Monetary Policy Regimes: An Application of Saphe Cracking

Rangan Gupta

University of Pretoria

Josine Uwilingiye

University of Pretoria

Working Paper: 2009-06

February 2009

Department of Economics

University of Pretoria

0002, Pretoria

South Africa

Tel: +27 124202413

Fax: +27 123625207 


\title{
COMPARING SOUTH AFRICAN INFLATION VOLATILITY ACROSS MONETARY POLICY REGIMES: AN APPLICATION OF SAPHE CRACKING
}

\author{
Rangan Gupta* and Josine Uwilingiye ${ }^{* *}$
}

\begin{abstract}
Recent empirical evidence on the direct link of inflation targeting and inflation volatility is at best mixed. However, comparing inflation volatility across alternative monetary policy regimes within a country based on conventional ways, used in previous studies, begs the question. The question is not whether the volatility of inflation has changed, but rather whether the volatility is different than it otherwise would have been. In such a backdrop, this paper uses the cosine-squared cepstrum to provide evidence that CPI inflation in South Africa has become more volatile since the first quarter of 2000, when the country moved into an inflation targeting regime, than it would have been had the South African Reserve Bank (SARB) continued with the more eclectic monetary policy approach pursued in the pre-targeting era.
\end{abstract}

JEL Codes: C65; E42; E52; E64.

Keywords: Cosine-Squared Cepstrum; Inflation Targeting; Inflation Volatility; Saphe Cracking.

\footnotetext{
* Corresponding author. Contact Details: Associate Professor, Department of Economics, University of Pretoria, Pretoria, 0002, South Africa. Phone: +27 12420 3460, Fax: +27 12362 5207, Email: Rangan.Gupta@up.ac.za.

** Graduate Student, Department of Economics, University Of Pretoria, Pretoria, 0002, South Africa. Phone: +27 72425 1121, Email: juwilingiye@yahoo.fr.
} 


\section{INTRODUCTION}

Recent empirical evidence on the direct link of inflation targeting and particular measure(s) of economic performance, in our case inflation volatility, is at best mixed. While, Neumann and Hargen (2002), Petursson (2004), Vega and Winkelfried (2005) and Mishkin and Schmidt-Hebbel (2007) finds inflation targeting has led to low inflation volatility, studies such as Johnson (2002), Truman (2003) and Ball and Sheridan (2005) tends to suggest otherwise. Essentially, all these studies and other papers ${ }^{1}$, analyzing the macroeconomic effects of inflation targeting, relies on empirical comparisons across inflation-targeting and non-targeting countries or within an inflation targeting country across monetary policy regimes, i.e., in the pre- and post-inflation targeting era. Though, comparisons across targeting and non-targeting countries are quite rational, studies that tend to compare within a country across regimes are flawed, and, hence, can only be viewed as providing preliminary evidence on the success or failure of inflation targeting. The reason is simple: When analyzing the effect of inflation targeting on the volatility of inflation, the real question is not whether the inflation volatility has increased or decreased since the central bank's decision to target inflation, but rather is the inflation rate more volatile than it would have been had the earlier monetary policy regime continued. To address this issue, we use what is called the cosine-squared cepstrum, and apply the technique to analyze the Consumer Price Index (CPI) inflation volatility in South Africa over the period of 1997:q1 to 2008:q2, which moved to an inflation targeting regime from the first quarter of $2000 .^{2}$

Note in the mid- to late-1990s, the South African Reserve Bank (SARB) took a more eclectic approach to monetary policy, which, essentially involved monitoring a wide range of indicators, such as changes in bank credit extension, overall liquidity in the banking sector, the yield curve, changes in official foreign reserves, changes in the exchange rate of the rand, and inflation movements and expectations. This approach was enhanced in 1998 by the replacement of the discount window by the marginal lending facility of the repurchase system and consequently, the Bank rate was replaced by the repo rate. The SARB altered their previously eclectic approach in February of 2000, when the Minister of Finance announced that inflation targeting would be the SARB's sole objective. Currently, the Reserve Bank's main monetary policy objective is to maintain CPIX ${ }^{3}$ inflation between the target-band of three to six percent, using discretionary changes in the repo rate as its main policy instrument.

Given that the SARB now targets inflation, if the move into the new regime or the abandonment of the older one affected inflation volatility, then observed inflation is

${ }^{1}$ See Mishkin and Schmidt-Hebbel (2007) for a detailed survey.

2 For a detailed summary on the history of monetary policy in South Africa, please refer to Naraidoo and Gupta (2009).

${ }^{3}$ CPIX is defined as CPI excluding interest rates on mortgage bonds. 
represented as the sum of two series: (i) the series that would have eventuated if the SARB continued to pursue its more eclectic approach to monetary policy, and (ii) a second series associated with the direct impact of the regime change that arrived in late 1999 or early 2000. If the regime had any coherent effect, then the two series are likely to be well correlated. If the second series is found to be positively correlated with the series that would have eventuated, then it increases the volatility of inflation and is said to be inphase. However, if the second series is negatively correlated or out of phase, volatility declines, since fluctuations in the series that would have eventuated are dampened. Generally speaking, if a time-varying stationary series is composed of two such series that are linear or well correlated, then the autocovariance function contains a global maximum at the zero lag and a local extremum at a lag corresponding to the date when the second series arrives. The problem with the autocovariance function is that it is difficult to detect a second series and determine the degree of its phase shift, given that a local extremum, in the case of an autocovariance function, appears as a broad cycle.

The cepstrum technique helps us to overcome such difficulties. Cepstra have been used successfully in detecting secondary influences in engineering, particularly communication theory. Intuitively, the cosine-squared cepstrum behaves like an autocovariance function, but with sharper resolution that helps in identifying the arrival and phase relationship of the secondary series with great precision. A local extremum appears as an impulse, instead of a broad cycle, the direction of which, in turn, determines whether the secondary series have increased or dampened volatility. Because of this, the cosinesquared cepstrum is well equipped to determine whether inflation volatility is greater than it would otherwise have been had the SARB continued to pursue its so-called eclectic approach to monetary policy decision-making.

The motivation to look into South Africa specifically, emanates from a recent study by Gupta and Uwilingiye (2008). This paper derives the econometric restrictions imposed by the Barro and Gordon (1983) model of dynamic time inconsistency on a bivariate timeseries model of CPI inflation and real Gross Domestic Product (GDP), and tests these restrictions based on quarterly data for South Africa covering the period of 1960:q1 through to 1999:q4, i.e., for the pre-inflation targeting period. The results show that the data are consistent with the short- and long-run implications of the theory of timeconsistent monetary policy. Moreover, when the model is used to forecast one-step-ahead inflation over the period of 2000:q1 to 2008:q2, i.e., the period covering the starting point of the inflation targeting regime till date the authors obtain, on average, obtain lower rates of inflation. The paper though is silent about inflation volatility that would have been generated over the inflation targeting era, if the SARB continued to be dynamically time inconsistent. But this is understandable, given that the Barro and Gordon (1983) model is essentially a framework for analyzing equilibrium inflation, and not its volatility. And this is exactly what this paper tries to address, as far as South Africa is concerned. It must be realized that for a country seeking price stability, it is not only essential to obtain lower mean levels of inflation but also less volatility in inflation. Inflation volatility matters because high variability of inflation over time makes expectations about the future price level more uncertain, which, in a world with nominal contracts, induces risk premia for long-term arrangements, raises costs for hedging against inflation risks and leads to unanticipated redistribution of wealth. Thus, inflation volatility can impede growth, even 
if inflation on average remains restrained. Given this, the current study is of paramount importance. To the best of our knowledge, this is the first attempt to study inflation volatility across monetary policy regimes by using the cosine-squared cepstrum. ${ }^{4}$ Finally note the decision to use quarterly data rather than monthly data for the CPI inflation rates is essentially an attempt to use the same data frequency as that of Gupta and Uwilingiye (2008) in drawing conclusions about the volatility of the inflation rates. For the same reason, we also used CPI rather than CPIX inflation.

An extended version of this study would be to evaluate the performance of all the inflation targeting economies with respect to not only inflation volatility, but also the volatility of output and the monetary policy instrument used to maintain the target or the target-band. The rest of the paper is organized as follows: Section 2 discusses cepstrum, while, Section 3 describes the data and our main findings. Finally, Section 4 concludes.

\section{THE CEPSTRUM 5}

If not in economics, the cepstrum is an integral transform with a long history. The use of the cepstrum dates back to Poisson (1823) and Schwarz (1872), who applied cepstra to problems involving potential functions with real parts fixed on the unit circle. Later, Szëgo (1915) and Kolmogorov (1939) used cepstra in the extraction of stable causal systems by factoring power spectra of random processes. However, it is the application of Bogert et al. (1963) in engineering that most coincides with our interest here.

Bogert et al. (1963) considers a time-varying function $f(t)$ which is made up of another function $f_{1}(t)$ and its additive "echo," $f_{1}(t-\tau)$, lagged by $\tau$ periods. Formally, we have:

$f(t)=f_{1}(t)+a f_{1}(t-\tau)$

The power spectrum of $f(t)$ is

$|F(\omega)|^{2}=\left|F_{1}(\omega)\right|^{2}\left\{1+a^{2}+2 a \cos (\omega \tau)\right\}$,

where $F_{1}(w)$ is the complex Fourier transform of $f_{1}(t)$. The "echo", in turn, manifests as a cosine function riding on the envelope of the power spectrum. The period of the cosine function is the reciprocal of the lag $\tau$. In studies involving autocorrelation analysis in hydroacoustic problems, Griffin et al. (1980) has shown that if the spectra of $f(t)$ and its "echo" differ, i.e., they are not perfectly correlated, then the parameter $a$ in Equation (2) varies with frequency. Thus, $f(t)$ is better represented by:

$f(t)=f_{1}(t)+f_{2}(t-\tau), \quad f_{1}(t) \neq f_{2}(t)$

so that the power spectrum of $f(t)$ is given by:

4 The only other paper that uses, and in fact, introduced the cosine-squared cesptrum to economics is by Cunnigham and Vilasuso (1994). The authors used the technique to compare Gross National Product (GNP) volatility across exchange rate regimes for the US economy.

5 This section relies heavily on the discussion available in Cunnigham and Vilasuso (1994). 
$|F(\omega)|^{2}=\left|F_{1}(\omega)\right|^{2}+\left|F_{2}(\omega)\right|^{2}+2\left|F_{1}(\omega)\right|\left|F_{2}(\omega)\right| \cos \left\{\phi_{1}(\omega)-\phi_{2}(\omega)+\omega \tau\right\}$,

where $\phi_{1}(\omega)$ and $\phi_{2}(\omega)$ are the phase spectra of $f_{1}(t)$ and $f_{2}(t)$, respectively.

The modulating cosine is phase-shifted by an amount which is equal to the differences in the phases of functions that composes $f(t)$. Thus, if the function $f_{1}(t)$ and $f_{2}(t)$ are not close copies of one another, the argument of the modulating cosine is not constant, which, in turn, has important consequences as we shall see below.

We proceed under the assumption that $f_{1}(t)=f_{2}(t)$ and return to the more general case later. The function $f(t)$ can be represented as the linear convolution of $f_{1}(t)$ with a train of impulses. Bogert et al. (1963) argue that if the envelope of $|F(\omega)|^{2}$ could be made optimally white, this would be equivalent to making $\left|F_{1}(\omega)\right|^{2}$ into a "boxcar" function, whose Fourier transform would be a sinc function at the origin. ${ }^{6}$ In the limit, as the envelope of the power spectrum becomes uniform at all frequencies, the sinc function tends towards a Dirac delta function. The transform of the modulating cosine would be an impulse whose delay is related to the frequency of the modulating cosine which, in turn, is equal to the lag length between $f_{1}(t)$ and its "echo." Therefore, under ideal conditions and when scaled properly, this resulting series yields a time domain function with a global maximum, or "peak" at the origin, and the local maximum or "peak" indicating the arrival time of the "echo."

In practice, the whitening of the power spectrum is performed by first applying the natural logarithm and then the inverse Fourier transform (IFT). Because it ignores the phase spectrum, and is calculated directly from the log power spectrum, the resultant function is referred to as the power spectrum.

Let us now go back to case presented in Equations (3) and (4). If the component functions are not close copies of one another, then the argument of the modulating cosine is not invariant, and, hence, cepstral peaks rapidly degenerate. Therefore, it must be realized that the impulse appears at the appropriate lag of the cepstrum only if the component functions are well correlated.

When we consider the discrete case, cepstra are a class of integral transform whose kernel is a function of the $z$-transform of a real sequence. The discrete power cepstrum of a data sequence $x(n T)$ with $z$-transform $X(z)$ is then given by:

$\tilde{x}(n T)=\frac{1}{2 \pi i}\left|\oint_{C} \log \right| X(z)\left|z^{n-1} d z\right|^{2}$

where $n=0,1,2, \ldots, N$, enumerates the samples, $T$ is the sampling interval, and $C$ is a closed contour inside the region of convergence of the power series and enclosing the origin. As discussed by Cunningham (1980), this can be extended to the cosine-squared cepstrum by addition of the signum function as follows:

\footnotetext{
${ }^{6}$ Note that $\operatorname{sinc} x=(\sin x) / x$.
} 
$\hat{x}(n T)=\tilde{x} \times \operatorname{sgn}\left\{\operatorname{Re}\left[\frac{1}{2 \pi i} \oint_{C} \log |X(z)| z^{n-1} d z\right]\right\}$

The addition of the signum function allows the cepstrum to determine not only the arrival time of the secondary series, but also, and perhaps more importantly, its polarity relative to the original series making its interpretation analogous to the autocovariance function. ${ }^{7}$ Because in real-life applications the real sequences $x(n T)$ are of finite length, the annulus of convergence of $X(z)$ always includes the unit circle, the transforms may be computed by means of the fast Fourier transforms.

Because the cepstrum is essentially the spectrum of a spectrum, the cepstral domain is a time domain. The terminology easily becomes confusing, therefore, Bogert et al. (1963) suggested the following conventions: the term "cepstrum" is an anagram of the word "spectrum." Likewise, periodicities in the cepstrum are discussed in terms of "quefrencies," "gamnitudes," and "repiods," analogous to "frequencies," "gain/amplitudes," and "periods" in the time domain. "Filtering" in the cepstral domain is "liftering" and so on. Further, Bogert et al. (1963) refers to data analysis in the cepstral domain as "alanysis". Finally, the term "saphe," pronounced "safe" and related to "phase," is used to refer to the displacement between the secondary, or lagged series, and the original. Thus, the detection and analysis of cepstral peaks and "phase" shifts of the lagged series is referred to as "saphe cracking."

\section{APPLICATION TO INFLATION VOLATILITY}

If the move to the inflation targeting regime affected the volatility of the CPI inflation rate for South Africa, then the series is representable as the sum of the pre-2000 series and a secondary series arriving in late 1999 or early 2000. If the secondary series are perfectly in-phase with the pre-2000 series, then volatility increased relative to what it would have been under the eclectic monetary policy regime; if it is perfectly out-of-phase, then volatility decreased. Determining whether or not a secondary series arrived and it was in-phase or out-of-phase is a straightforward application of the cosine-squared cepstrum, discussed in Section 2.

We begin by performing unit root tests on the CPI inflation rate, since the application of the cosine-squared cepstrum requires us to ensure that the data process is stationary. For this purpose we use the Augmented-Dickey-Fuller (ADF) test, the Dickey-Fuller test with GLS Detrending (DF-GLS), the Kwiatkowski, Phillips, Schmidt, and Shin (KPSS) test and the Phillips- Perron (PP) test. As can be seen from Table 1, seasonally adjusted (at annual rate) CPI inflation is found to follow an autoregressive process with a unit root, as the null hypothesis of a unit root could not be rejected for the variables,

7 The close relationship between the cosine-squared cepstrum and the autocovariance function becomes clear when we write the latter as a function of the z-transform of the same series: $x_{\text {acvf }}(\tau)=\frac{1}{2 \pi i} \oint_{c}|X(z)| z^{n-1} d z$. Equivalently, the autocovariance function is the inverse Fourier transform of the power spectrum of a series. 
expressed in levels for the ADF, the DF-GLS and the PP tests, while for the KPSS test, the null of stationarity was rejected. As both the variables were found to be nonstationary, we had to first difference the inflation rates. Following Cunningham and Vilasuso (1994), we start our analysis 12 quarters prior to the change in regime, so the first-differenced CPI inflation series begins at 1997:q1. ${ }^{8}$ Once the first-differenced CPI inflation series was generated and found to be stationary, we demean the series to avoid the dominance of the zero frequency components in the power spectrum, and then apply the five point Hanning-type cosine tapers to suppress possible sidelobes. Next we use a Cooley-Tukey fast Fourier transform (FFT) and compute the natural logarithm of the sum of squares of the real and imaginary parts to form the log power spectrum. Forming the inverse FFT (IFFT) and then the sum of squares again, and establishing the sign according to the sign of the real part, the cosine-squared cepstrum is formed, as discussed in Equation (6).

\section{TABLE 1: UNIT ROOT TESTS}

\begin{tabular}{|c|c|c|c|c|c|c|c|}
\hline \multirow{2}{*}{ Series } & \multirow{2}{*}{ Model } & \multicolumn{2}{|c|}{ ADF } & \multirow{2}{*}{$\begin{array}{l}\mathrm{PP} \\
\tau_{\tau} \tau_{\mu} \tau\end{array}$} & \multirow{2}{*}{$\begin{array}{l}\text { KPSS } \\
\tau_{t} \tau_{\mu}\end{array}$} & \multirow{2}{*}{$\begin{array}{l}\text { DF-GLS } \\
\tau_{t} \tau_{\mu}\end{array}$} & \multirow{2}{*}{ Conclusion } \\
\hline & & $\tau_{\tau} \tau_{\mu} \tau$ & $\phi_{3} \phi_{1}$ & & & & \\
\hline \multirow[t]{3}{*}{ CPI_INFL } & $\tau_{t}$ & -2.85 & 4.65 & -3.03 & 0.11 & -2.86 & \multirow[t]{3}{*}{ Non- stationary } \\
\hline & $\tau_{\mu}$ & -2.90 & $8.40^{* * *}$ & $-3.08^{* *}$ & 0.10 & $-2.52^{* *}$ & \\
\hline & $\tau$ & -1.36 & & -1.34 & & & \\
\hline \multirow[t]{3}{*}{ D(CPI_INFL) } & $\tau_{t}$ & $-6.39^{* * *}$ & $20.42^{* * *}$ & $-7.33^{* * *}$ & $0.12^{*}$ & $-6.19^{* * *}$ & \multirow[t]{3}{*}{ Stationary } \\
\hline & $\tau_{\mu}$ & $-6.38 * * *$ & $40.65^{* * *}$ & $-7.04 * * *$ & 0.30 & $-5.82 * * *$ & \\
\hline & $\tau$ & $-6.44^{* * *}$ & & $-7.11 * * *$ & & & \\
\hline
\end{tabular}

Notes: (i) CPI_INFL stands for CPI inflation;

(ii) $\mathrm{D}$ (CPI_INFL) is the first difference of CPI inflation.

Figure 1 shows the first 23 lags of the cosine-squared cepstrum for first-differenced CPI inflation. For the sake of convenience, the time scale replaces the lag numbers. The first nine points of the cepstrum for the first-differenced CPI inflation rate is rescaled to enhance the detail. ${ }^{9}$ A delta function spikes upward prominently at the lag corresponding to the first quarter of 2000. This "arrival time" for the secondary series is consistent with

${ }^{8}$ The data for this paper are from the quarterly bulletins available for download from the official website (http://www.reservebank.co.za/) of the SARB. All the computations are performed by using the Signal Processing Toolbox in MATLAB, Version R 2007a.

${ }^{9}$ The first nine cepstral estimates for the first-differenced CPI inflation rate is set equal to zero to enhance the detail. The above operation removes the delta function at the origin, which, in turn corresponds to the global maximum. 
the announcement of the Finance Minister that inflation targeting would be the SARB's sole objective. The unambiguous nature of the delta function and its positive sign provide evidence of a secondary influence on the South African CPI inflation series that not only matched it fluctuation by fluctuation, but was also exactly in-phases with the CPI inflation series. In other words, the secondary influence that arrived in early 2000 has increased the fluctuations/volatility in the CPI inflation rate.

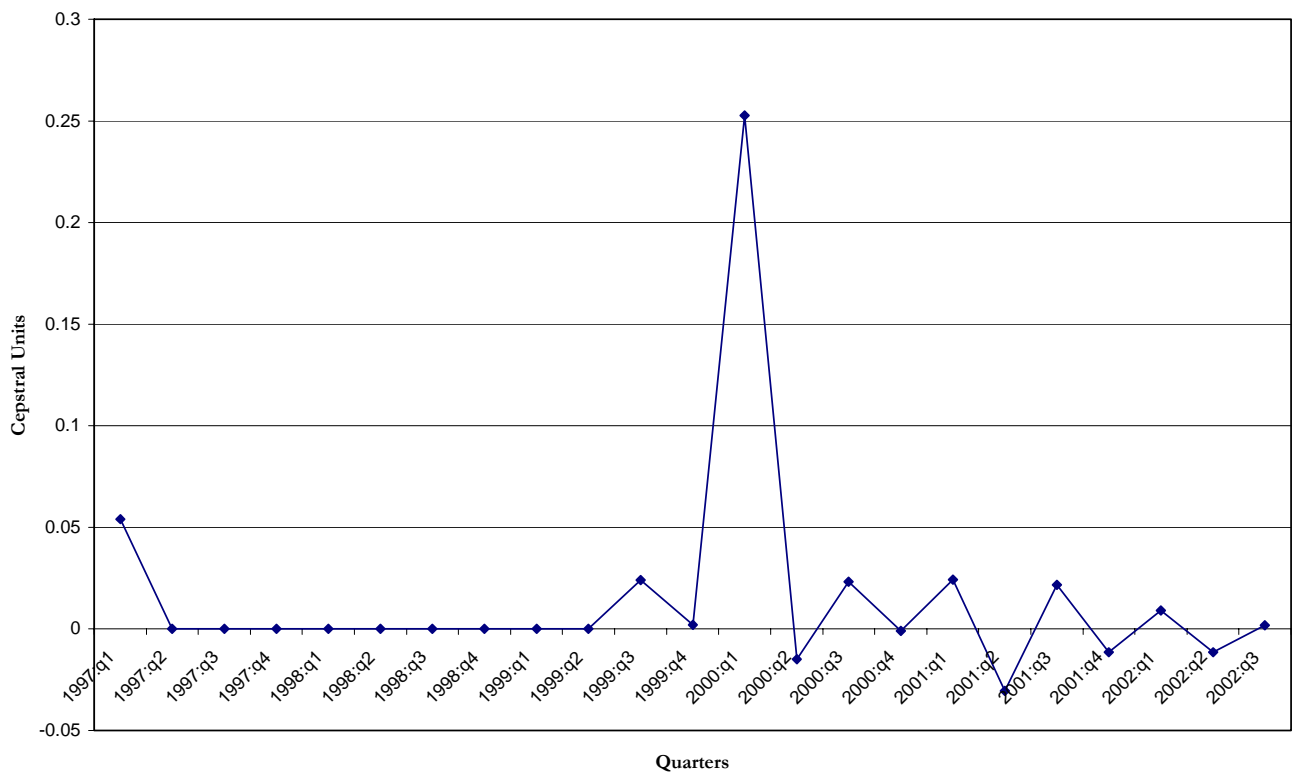

Figure 1: The Cosine-Squared Cepstrum of the CPI inflation, 1997q1-2008q2.

Gupta and Uwilingiye (2008) have previously indicated that had the SARB continued to be time inconsistent it would have produced lower average levels of inflation in the post inflation targeting period. Here we show that the inflation-targeting regime has increased the volatility of inflation relative to what it would have been under the eclectic monetary policy regime. So in other words, it seems, the SARB has failed to attain its primary objective of inflation targeting, which is price stability in terms of both the mean and variance of inflation, at least until now.

\section{CONCLUSIONS}

The positive delta function in the cosine-squared cepstrum has provided evidence that the inflation targeting regime in South Africa began to impact CPI inflation in the first quarter of 2000, making the same more volatile than it would have been had the SARB pursued the more eclectic monetary policy approach, which was in place prior to the 2000:Q1. The cosine-squared cepstrum, thus, shows promise in application where the effects of economic events and policy changes on time series data can be modelled as additive time series that are well correlated with the series under study. However, there 
are limitations to this approach. For example, the increased inflation volatility under the new monetary policy regime may not be permanent, but rather a pulse-like response in the inflation rate. Moreover, without recovering the secondary series, the method requires outside information for the identification of cepstral peaks. While a prominent cepstral peak, like the one we have, is relatively unambiguous in terms of its timing and phase characteristics, it takes additional economic insight to isolate the possible economic causes of the event. Therefore, without the recovery of the secondary series, the cepstrum is limited only to studies in which response to a possible event can be clearly isolated in time.

Despite the limitations, the finding of increased inflation volatility in the inflation targeting regime indicated by the positive delta function in the cosine-squared cepstrum cannot be taken lightly. In our opinion, the possible explanation for the increased fluctuations in the CPI inflation lies in the width of the target band of 3 percent to 6 percent. Mishkin (2003) points out that "the use of target bands has a dangerous aspect. Floors and ceilings of bands can take on a life of their own in which there is too great a focus on the breach of the floor or ceiling rather than on how far away actual inflation is from the midpoint of the target range." Too much focus on breaches of the floors or ceilings, in turn, can lead to the so-called instrument instability problem (Bernanke et al. (1999) and Mishkin and Schmidt-Hebbel (2002)). Moreover, it can also lead to suboptimal setting of monetary policy and controllability problems resulting in the inflation target to be missed in the medium-term Mishkin (2003). In this regard, as pointed out by Demertzis and Viegi (2006, 2007, and 2008), a narrower, and possibly also a lower, target band could be of immense help in improving the central bank's credibility and causing inflation expectations to converge to a focal point, and hence, bring down the mean and variance of the inflation rate.

\section{REFERENCES}

BALL, L. and SHERIDAN, N. (2005). Does Inflation Targeting Matter? In Bernanke Ben S \& Michael Woodford (eds). The inflation Targeting Debate, NBER Studies in Business Cycles, Vol. 32. Chicago: University of Chicago Press.

BARRO, R.J. and GORDON, D.B. (1983). A positive Theory of Monetary Policy in a Natural rate Model. Journal of Political Economy, 91:589-610.

BERNANKE, B.S., LAUBACH, T., MISHKIN, F.S. and POSEN, A.S. (1999). Inflation targeting: lessons from the International Experience. Princeton, NJ: Princeton University Press.

BOGERT, B.P., HEALY, M.J.R. and TUKEY, J.W. (1963). The Quefrency Alanysis of Time Series for Echoes: Cepstrum, Pseudo-Autocovariance, Cross -Cepstrum, and Saphe Cracking. IN proceedings of a Symposium on Time Series Analysis, edited by Murray Rosenblatt. New York: John Wiley \& Sons, Inc., 1963.

CUNNINGHAM, S.R. (1980). Application of Cepstral Techniques to Rayleigh Wave Multipathing. U.S. national Technical Information Service (NTIS), ENSCO DCS-STR$80-45$.

CUNNINGHAM, S.R and VILASUSO, J. (1994). Comparing U.S. GNP Volatility across Exchange Rate Regimes: An Application of Saphe Cracking. Journal of Macroeconomics, 16: 445-459. 
DEMERTZIS, M. and VIEGI, N. (2006). Aiming for the Bull's Eye: Uncertainty and Inertia in Monetary Policy. Computing in Economics and Finance 2006 150, Society for Computational Economics.

DEMERTZIS, M. and VIEGI , N. (2007). Inflation Targeting - a Framework for Communication. DNB Working Papers 149, Netherlands Central Bank, Research Department.

DEMERTZIS, M. and VIEGI, N. (2008). Inflation Targets as Focal Points. International Journal of Central Banking, 4: 55-87.

GRIFFIN, J.N., JONES, R.. L. and CUNFER, R. S. (1980). Experimental Procedures for Estimating Depths and Yields of Underwater Explosions Using Recordings of Limited Dynamic Range. Final Report, Project T/ 8152/, ENSCO.

GUPTA, R. and UWILINGIYE, J. (2008). Should the SARB have Stayed Time Inconsistency? Working paper No 200833, Department of Economics, University of Pretoria.

JOHNSON, D.R. (2002). The effect of inflation targeting on the behavior of expected inflation: evidence from an 11 country panel. Journal of Monetary Economics, 49: 1521-1538.

KOLMOGOROV, A. N. (1939). Sur l'interpolation et extrapolation des suites stationnaires. Compte Rendus Hebdomadaires des Séances de l'Academie des Sciences, 208: 20432045.

MISHKIN, F.S. and SCHMIDT-HEBBEL, K. (2002). One decade of inflation targeting in the world: What do we know and what do we need to know? In Norman Loayza and

Raimundo Soto (eds). Inflation targeting: Design, Performance, Challenges, 171-219. Central Bank of Chile.

MISHKIN, F.S (2003). A Comment on "Inflation Targeting in Emerging Market Economies" by Arminio Fraga, Ilan Goldfajn and Andre Minella, NBER Macro Annual, 2003, 403-413.

MISHKIN, F.S. and SCHMIDT-HEBBEL, K. (2007). Does Inflation Targeting Make Difference? NBER Working Paper No. W12876.

NARAIDOO, R. and GUPTA, R. (2009), Modelling Monetary Policy in South Africa: Focus on Inflation Targeting Era Using a Simple Learning Rule, Working paper No 200904 , Department of Economics, University of Pretoria.

NEUMAN, M.J.M. and VON HAGEN, J. (2002). Does Inflation Target Matter? Review (Federal Reserve Bank of St. Louis), 84: 127-148.

PETURSSON, T.G. (2004). The effects of inflation targeting on macroeconomic performance. Working paper 23, Central Bank of Iceland.

POISSON, S.D. Sur la distribution de la chaleur dans les corps solides. Journal de l'Ecole Polytechnique, 19:1-162

SCHWARZ, H.A. (1872). Zur Integration de partiellen Differentialgleichung. Journal fur die Reine und Angewandte Mathematik, 74: 218-254.

SZËGO, G. (1915). Ein Grenzwertsatz uber die Toeplitzschen Determinanten einer reellen positiven Funktion. Mathematische Annalen, 76: 490-503.

TRUMAN, E.M. (2003). Inflation Targeting in the World Economy. Washington, DC: Institute for International Economics.

VEGA, M. and WINKELFRIED, D. (2005). Inflation Targeting and Inflation Behavior: A Successful Story? International Journal of Central Banking, 1:153-175. 